\title{
PRESERVATION OF AVOCADO PULP FOR THE APPLICATION IN FOOD INDUSTRY
}

\author{
V.L.Rajapaksha \\ Reg. No. : - MFS/341 \\ The thesis is submitted to the University of Sri Jayawardenapura \\ for the award of the Degree of \\ Master of Science \\ In \\ Food Science and Technology
Department of Food Science and Technology
Faculty of Graduate Studies
University of Sri Jayawardenapura
Gangodawila
Nugegoda

August 2015 
AFFECTIONATE DEDICATION TO

MY FAMILY AND TEACHERS 


\section{Declaration}

The work described in this thesis was carried out by me under the supervision of Dr.S.B.Navarathne, Department of Food Science and Technology, Faculty of Applied Sciences, University of Sri Jayawardenepura and a report on this has not been submitted in whole or in part to any university or any other institution for another Degree/Diploma.

V.L.Rajapaksha

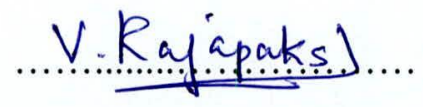

MFS/341

Date: $-\ldots .08 / 12 / 2015$

I certify that the above statement made by the candidate is true and that this thesis is suitable for submission to the University for the purpose of evaluation.

Certified by,

Dr.S.B.Navarathne,

Supervisor,

Department of Food Science and Technology,

Faculty of Applied Sciences,

University of Sri Jaywardenepura,

Gangodawila,

Nugegoda,

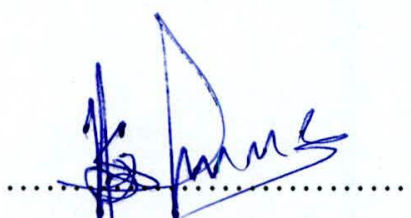

Date: $-\ldots \ldots 1.2 .1 .12 .2015$

Sri Lanka. 


\begin{abstract}
The avocado is a rather unique type of fruit. It is one of the most productive plants around the world. The flesh is hard when harvested but optimally ripe avocados are contain silky, creamy texture and rich flavours. Mature fruit do not ripen and soften on the tree. Fruits plucked at immature stage are of inferior quality. It's a climacteric fruit hence ripens only after detaching from the mother plant. Avocado is a highly perishable fruit. Substantial amount of fruit is lost due to poor post-harvest practices and seasonal nature of the produce.
\end{abstract}

In this study, the best method to preserve avocado powder as natural as possible was determined. Corn starch was used as an inert filler to increase the drying rate. The nutritional composition of the preserved powder was determined to check whether any nutritional loss or gain was achieved by the preservation. The suitability of the preserved powder was checked for the application in the food industry.

According to the findings, cold air dehumidifying method was selected over hot air oven drying as the best preservation method. Apart from avocado pulp only corn starch was used. Blanching (boiling hot water 30 seconds) was done to deactivate the enzymes which causes browning of the avocado pulp when exposed to air for a few hours. Proximate analysis revealed that the preserved powder in $100 \mathrm{~g}$ contains protein $1.5 \mathrm{~g}$, fat $6.8 \mathrm{~g}$, fiber $2.2 \mathrm{~g}$, ash $0.4 \mathrm{~g}$, moisture $1.5 \mathrm{~g}$ and carbohydrate $89.8 \mathrm{~g}$. 


\section{ACKNOWLEDGEMENT}

I wish to express my foremost gratitude to my supervisor Dr.S.B.Navarathne, Department of Food Science and Technology, Faculty of Applied Science, University of Sri Jayawardenepura, for his priceless supervision and kind corporation rendered to me to complete the project successfully.

I would also like to thank our coordinator of the food science and technology MSc programme, Dr.M.A.J.Wansapala, for guiding us throughout the MSc degree programme.

I also extend my thanks to the staff members of the Department of Food Science and Technology, Faculty of Applied Sciences, University of Sri Jayawardenepura for the valuable support given to me.

My special thanks to the laboratory staff of Department of Food Science and Technology, Faculty of Applied Sciences, University of Sri Jayawardenepura for their kind assistance given to me.

I'm also grateful for my family and my colleagues for their never ending support throughout this research. 


\section{LIST OF FIGURES}

Figure 2.1 Global distribution map of avocado 6

Figure 2.2 Parts of an avocado seed 9

$\begin{array}{ll}\text { Figure 2.3 The Avocado fruit } & 10\end{array}$

$\begin{array}{ll}\text { Figure 2.4 Pollock Variety } & 11\end{array}$

$\begin{array}{lr}\text { Figure } 2.5 \text { Purple Variety } & 12\end{array}$

$\begin{array}{ll}\text { Figure 2.6 Fuerte Variety } & 13\end{array}$

$\begin{array}{ll}\text { Figure } 2.7 \text { Booth }-7 \text { Variety } & 13\end{array}$

$\begin{array}{ll}\text { Figure 2.8 Simmonds Variety } & 14\end{array}$

$\begin{array}{ll}\text { Figure 2.9 Avocado Fruit Ripening Stages } & 17\end{array}$

Figure 3.1 Avocado 20g + Corn Starch 15g 28

Figure 3.2 Different Avocado: Corn Starch Ratios 28

Figure 4.1 After Hot Air Oven Drying $\quad 37$

Figure 4.2 After Cool Air Dehumidifying Drying 37

Figure 4.3 Preserved Avocado Pulp and Corn Starch Powder 40

Figure 4.4 Web Diagram of Sum of Ranks of 351,451 and 551 Samples 47

Figure 4.5 Web Diagram of Est Median of 351, 451 and 551 Samples 48

Figure 4.6 Web Diagram of Sum of Ranks of Samples A and B 51

Figure 4.7 Web Diagram of Est Median of Samples A and B 52 


\section{LIST OF TABLES}

Table 2.1 Major Countries Producing Avocado $\quad 7$

Table 2.2 Average Nutrition Composition of Avocado Fruit 22

Table 3.1 Different Combinations of Avocado Pulp and Corn Starch 27

Table 3.2 Recipes of the Two Samples 34

Table 4.1 Observations and Results of the Hot Air Oven Dried and Cold Air

Dehumidifier Dried Samples $\quad 35$

Table 4.2 Observations and Results of Different Avocado Pulp and Corn starch

Ratios in Cold Air Dehumidifying Method 38

Table 4.3 Corn Starch Nutritional Composition 41

Table 4.4 Avocado Pulp Nutritional Composition 42

Table 4.5 Proximate Analysis Results of Preserved Avocado Powder $\quad 42$

Table 4.6 Descriptive Analysis Results of Different Avocado Pulp: Corn Starch

$\begin{array}{ll}\text { Ratios } & 45\end{array}$

Table 4.7 Sum of Ranks of 351, 451 and 551 Samples 46

Table 4.8 Estimated Median of 351, 451 and 551 samples 47

Table 4.9 Descriptive Analysis Results of Comparison between Original

Avocado Beverage and Preserved Powder Beverage 49

Table 4.10 Sum of Ranks of samples A and B 50

Table 4.11: Estimated Median of Samples A and B 51 


\section{ABBREVIATIONS}

IU - International Units

$\mathrm{g}$ - grams

$\mathrm{mg}-$ milligrams

HDL - High Density Lipoprotein

LDL - Low Density Lipoprotein 


\section{TABLE OF CONTENTS}

$\begin{array}{lr}\text { Abstract } & \text { i } \\ \text { Acknowledgment } & \text { ii } \\ \text { List of figures } & \text { iii } \\ \text { List of tables } & \text { iv }\end{array}$

Abbreviations $\quad$ v

Chapter 1 - Introduction

1.1 Introduction 5

1.2 General objective $\quad 6$

$\begin{array}{ll}1.3 \text { Specific objectives } & 6\end{array}$

Chapter 2 - Literature survey

$\begin{array}{ll}2.1 \text { Introduction to avocado } & 7\end{array}$

$\begin{array}{ll}\text { 2.1.1 Origin and distribution } & 7\end{array}$

$\begin{array}{ll}2.1 .2 \text { Avocado production } & 8\end{array}$

$\begin{array}{ll}\text { 2.1.3 Taxonomy and classification } & 10\end{array}$

$\begin{array}{ll}2.2 \text { Botany } & 11\end{array}$ 
2.3.1 Pollock

2.3.2 Purple varieties

2.3.3 Fuerte

2.3.4 Booth -7

2.3.5 Simmonds

2.4 Propagation

2.5 Fruit development

2.6 Fruit ripening

2.7 Harvesting

2.8 Diseases and pests

2.9 Environmental conditions required for avocado cultivation

2.9.1 Climate

2.9.2 Soil, water and fertilizer

2.10 Nutrition composition of avocado

2.11 Health and nutritional benefits of Avocado 


\section{Chapter 3 - Materials and Methods}

3.1 Materials and reagents

3.2 Methods

3.2.1 Selection of samples

3.2.2 Sample preparation

3.3 Proximate analysis

3.3.1 Determination of protein

3.3.2 Determination of fiber

3.3.3 Determination of ash

3.3.4 Determination of fat

3.3.5 Determination of moisture

3.3.6 Determination of carbohydrate 35

3.3.7 Determination of $\mathrm{pH}$

3.3.8 Determination of energy

3.4.1.1 Determination of best avocado pulp: corn starch evaluation 36

3.4.1.2 Original avocado beverage in compare with preserved powder beverage 


\section{Chapter 4 - Results and Discussion}

4.1 Identification of best preservation method

4.2 Identification of best preservation ratio of avocado pulp: corn starch

4.3 Determination of nutritional composition of the preserved avocado pulp powder

4.4.1.1 Best avocado pulp: corn starch ratio evaluation

4.4.1.2 Original avocado beverage in comparison with the preserved powder beverage 50

Chapter 5 - Conclusion

Chapter 6 - Recommendations

References

Appendix

58 


\section{CHAPTER 1}

\section{INTRODUCTION}

\subsection{Introduction}

The avocado (Persea americana) is a tree native to Mexico and Central America, categorized in the flowering plant family Lauraceae. It's now grown throughout the tropical and subtropical countries. It's an edible fruit which also goes by the name "alligator pear" due to the skin texture of some varieties which is similar to that of an alligator (leather-like skin). It also goes under the name of aguacate, butter pear.

Avocados are considered a fruit because they fit all of the botanical criteria for a berry. It's called a single-seeded berry. The fruit is a pear shaped drupe ( round and oblong shaped fruit varieties are also available) of olive green colour and with a rough surface with a yellowish green flesh with a buttery consistency and a large central stone but varieties without stones can also be found. The skin is smooth to coarse, and the colour can vary from green-yellow, reddish-purple, purple, or black.

There are approximately 400 varieties and fruits of different weights reaching up to $2 \mathrm{~kg}$ can be found. According to the department of agriculture only few species of avocados are grown in Sri Lanka. They are Pollock, Purple varieties, Fuerte, Booth - 7, Simmonds, Tower 11. Those varieties are majorly grown in Kandy, Matale, Nuwara Eliya, Badullla and Kegalle.

The best indicator of ripeness is the colour of the flesh itself. The pulp of ripe avocados are creamy and pale green. Ripening occurs after detaching from the mother plant. 
The growers select avocado as a permanent crop due to their excellent adaptability to the climatic conditions of the wet zone, particularly their tolerance to rainfall during flowering and with less demand for crop agriculture practices and few pest and disease problems.

Avocados are considered as a super food due to their high nutritional values and multiple benefits for the health of the human beings. Avocados, are high in mono-unsaturated fats and calories. They are a powerhouse of heart-healthy fats and brain-boosting omega fatty acids. They are very rich in dietary fiber, vitamins, and minerals and packed with numerous health benefiting plant nutrients.

Avocado is a highly perishable fruit. Substantial amount of fruit is being lost due to poor harvest practices and seasonal nature of the produce.

Preservation of avocado pulp is a value addition process and preserved pulp may also help to product diversification. Aim of this study is exploring various avenues to preserve avocado pulp as much natural as possible.

\subsection{General objective}

To formulate an avocado based dry powder for the application in food industry.

\subsection{Specific objectives}

- To identify the best method of preservation.

- To determine the nutritional composition of the preserved powder.

- To determine the suitability of preserved powder in different food products. 


\section{CHAPTER 2}

\section{LITERATURE REVIEW}

\subsection{Introduction to avocado}

Avocados are commercially valuable and cultivated in tropical climates throughout the world, producing a green skinned, pear shaped fruit that ripens after harvesting. They are climacteric fruits. When harvesting flesh is hard but it softens with the ripening. Avocado fruits have green-yellow flesh with a buttery evenness and a rich, nutty flavour. The flesh contains oil $19 \%$. Among the nutrients in avocados are thiamin, riboflavin and vitamin A. they have important medicinal values such as reducing cholesterol level in blood. They are still one of the most abundant and greatly important food commodity around the world.

\subsubsection{Origin and distribution}

When Spanish people began wide surveys in both North and South America after their discovery, the avocado tree was being cultivated for fruit by various peoples all the way from central Mexico to Northern Peru. Avocados are classified within three ecologically distinct subspecies known as the Guatemalan, Mexican and West Indian races. Its natural range covers diverse environmental conditions from the central highlands of Mexico where frosts occur to the rain forests of northwest Columbia. The first introduction of avocado into Sri Lanka is not well documented, but some evidence suggests that it could have been originally domesticated during the Dutch occupation, over 200 years ago. The first recorded introduction was made on $12^{\text {th }}$ May 1927 during the British employment of the island. (Gunasekara, 2011) 